\title{
Структурные изменения в пленках кремний-на-изоляторе нанометровой толщины при высокотемпературном отжиге
}

\author{
(C) И.Е. Тысченко ${ }^{1}$, Е.В. Спесивцев ${ }^{1}$, А.А. Шкляев ${ }^{1,2}$, В.П. Попов ${ }^{1}$ \\ ${ }^{1}$ Институт ффизики полупроводников им. А.В. Ржанова Сибирского отделения Российской академии наук, \\ 630090 Новосибирск, Россия \\ ${ }^{2}$ Новосибирский государственный университет, \\ 630090 Новосибирск, Россия \\ E-mail: tys@isp.nsc.ru
}

Поступила в Редакцию 10 ноября 2021 г.

В окончательной редакции 15 ноября 2021 г.

Принята к публикации 15 ноября 2021 г.

\begin{abstract}
Термическая стабильность пленок кремний-на-изоляторе толщиной 4.7 и 2.2 нм исследовалась в зависимости от температуры отжига в интервале $T=800-1200^{\circ} \mathrm{C}$ методами сканирующей электронной микроскопии и спектральной эллипсометрии. Никаких признаков плавления пленок не наблюдалось, пленки оставались протяженными в указанном интервале температур. Обнаружено уменьшение толщины пленок и изменение их фазового состава с ростом температуры. По данным спектральной эллипсометрии, с увеличением температуры отжига доля кристаллической фазы в пленках уменьшается, а доля аморфной растет. Определена энергия активации процесса аморфизации пленок. Обнаруженный эффект обсуждается с точки зрения диффузии атомов кислорода в пленку кремния и перестройки $\mathrm{Si}-\mathrm{Si}-$ связей.
\end{abstract}

Ключевые слова: кремний-на-изоляторе, термическая стабильность, наноструктуры, аморфизация.

DOI: $10.21883 /$ FTP.2022.03.52118.9766

\section{1. Введение}

Начиная с 1990-х годов структуры кремний-на-изоляторе (КНИ) заняли прочное положение в современной электронике как альтернатива подложкам монолитного кремния при создании сверхбольших интегральных схем в силу целого ряда их преимуществ, обусловленных меньшим объемом кремния, возможностью изоляции отдельных элементов интегральных схем, снижением паразитных токов, устранением эффекта защелкивания и др. [1]. Однако современные тенденции развития электроники требуют создания структур со слоями кремния и диэлектрика толщиной в несколько нанометров. Дальнейшее использование таких структур в кремниевой технологии может быть осложнено снижением термической стабильности пленок нанометровой толщины. Это связано с тем, что уменьшение толщины слоя кремния до нескольких нанометров сопровождается увеличением вклада поверхности в свойства слоя кремния. Как следствие, это может привести к изменению усредненного значения координационного числа атомов кремния и усредненного угла между $\mathrm{Si}-\mathrm{Si}$-связями. В результате с уменьшением толщины слоя может происходить изменение энергии связи, приходящейся на 1 атом кремния. Этот эффект может сильно изменяться с увеличением температуры, а именно сопровождаться изменением температуры плавления по сравнению с температурой плавления объемного кристалла.

Экспериментально термическая нестабильность пленок КНИ нанометровой толщины наблюдалась в работах [2-5] после отжига в высоком вакууме. В частности, в работе [5] была обнаружена агломерация пленок КНИ толщиной $1.1-1.5$ нм уже после отжига при температуре $\sim 570^{\circ} \mathrm{C}$. С увеличением толщины пленки до 3-6 нм температура, при которой наблюдалось образование капель кремния на поверхности $\mathrm{SiO}_{2}$, возрастала до $825-850^{\circ} \mathrm{C}$ соответственно. В работе [6] было установлено, что размеры кремниевых капель, формирующихся в результате агломерации, зависят от толщины пленки КНИ. Их высота и латеральные размеры увеличиваются с ростом толщины слоя кремния. Авторы [6] связывают эту зависимость с термическими процессами, поскольку температура образования капель увеличивается с ростом толщины пленки.

В литературе попытки описать теоретически изменение температуры плавления с уменьшением размера частицы предпринимались неоднократно. Еще в 1908 году П. Павловым была развита термодинамическая модель, которая впервые предсказывала снижение температуры плавления с уменьшением размера частицы [7]. В 1910 году Ф. Линдеманном [8] была предложена модель плавления, в основе которой лежал подход, основанный на динамических изменениях кристаллической решетки с ростом температуры. А именно средняя амплитуда тепловых колебаний в решетке увеличивается с ростом температуры. Был сформулирован критерий Линдеманна, который гласит, что отношение средней амплитуды колебаний атомов к межатомному расстоянию в твердом теле при температуре плавления есть величина постоянная [8]. Поскольку атомы на поверхности связаны слабее, то в реальных условиях это может приводить к бо́льшим амплитудам колебаний при той же температуре, чем у атомов, находящихся в объеме частицы или тонкой пленки. Иными словами, согласно 
критерии Линдеманна, процесс плавления твердого тела должен начинаться с поверхности. Для слоев нанометровой толщины это может сопровождаться в целом снижением эффективной температуры плавления пленки, поскольку вклад атомов на поверхности становится достаточно большим.

Модели Павлова [7] и Линдеманна [8] не учитывали ни формы кристалла, ни матрицы, в которой он находится, или сред, с которыми граничит. В 1948 году в работе [9] была предложена термодинамическая модель плавления, которая учитывала не только размер кристалла, но и его форму, а также условия на границах раздела. В частности, теоретически были изучены особенности изменения температуры плавления сферических кристаллов с малыми размерами, тонких протяженных пленок и тонких нитей. В рамках предложенной модели было установлено, что температура плавления сферической частицы с уменьшением ее диаметра падает. Для тонкой пленки эффект влияния толщины пленки на температуру плавления неоднозначен, и она может изменяться как в сторону понижения, так и в сторону повышения, в зависимости от того, какова химическая природа вещества, с которым данная пленка граничит.

Модель, рассматривающая изменение температуры плавления наночастиц с уменьшением их размера за счет увеличения амплитуды колебаний атомов, в которой учитывалось взаимодействие атомов наночастицы с атомами на поверхности или в окружающей матрице, предложена в работе [10]. Авторами [10] было показано, что и для сферических наночастиц возможны ситуации, создающие условия как для уменьшения, так и для увеличения температуры плавления при уменьшении размера частицы или толщины пленки.

Итак, анализ литературных данных показывает, что уменьшение размерности кристалла может неоднозначно сказаться на изменении его термической стабильности. Поэтому цель настоящей работы заключалась в исследовании термической стабильности и структурных изменений в пленках кремний-на-изоляторе нанометровой толщины в условиях высокотемпературного отжига в печи при нормальном атмосферном давлении.

\section{2. Методика экспериментов}

Экспериментальные образцы были изготовлены методом DeleCut на технологической линейке КНИ и КНС Института физики полупроводников им. А.В. Ржанова [1]. В качестве исходного материала использовались пластины монокристаллического кремния марки КЭФ-4.5 с ориентацией (100). Сначала на первой пластине кремния с помощью термического окисления в атмосфере влажного кислорода при $T=1100^{\circ} \mathrm{C}$ был выращен слой $\mathrm{SiO}_{2}$ толщиной $\sim 300$ нм. Затем во вторую пластину кремния, на которой предварительно в атмосфере сухого кислорода при $T=900^{\circ} \mathrm{C}$ был выращен защитный слой $\mathrm{SiO}_{2}$ толщиной 20 нм, проводилась имплантация ионов водорода $\mathrm{H}_{2}^{+}$с энергией 120 кэВ дозой $2.7 \cdot 10^{16} \mathrm{~cm}^{-2}$. После имплантации ионов водорода проводилось удаление защитного слоя $\mathrm{SiO}_{2}$ в растворе $\mathrm{HF}: \mathrm{H}_{2} \mathrm{O}=1: 100$. Затем первую пластину соединяли окисленной стороной с имплантированной стороной второй пластины, и при температуре $450^{\circ} \mathrm{C}$ в вакууме проводилось расслоение по слою, имплантированному водородом, с одновременным переносом пленки кремния толщиной $\sim 540$ нм. Полученная КНИ пластина была подвергнута многоступенчатому термическому окислению во влажном кислороде при $T=1000^{\circ} \mathrm{C}$ и в сухом кислороде при $T=850-950^{\circ} \mathrm{C}$, в результате чего были выращены слои оксида кремния, после удаления которых толщина оставшихся слоев КНИ составляла 4.7 и 2.2 нм. На поверхности КНИ слоев сохранялся слой естественного окисла толщиной 1 и 1.4 нм соответственно. Последующий отжиг образцов проводился в печи в потоке паров $\mathrm{N}_{2}$ при температурах $800-1200^{\circ} \mathrm{C}$ в течение 15 мин.

Свойства изготовленных КНИ структур исследовались методами сканирующей электронной микроскопии (СЭМ) и спектральной эллипсометрии. В наших экспериментах исследования морфологии поверхности образцов методом СЭМ проводились в системе электроннолучевой литографии высокого разрешения RaithPioneer. Ускоряющее напряжение электронного пучка составляло 10 кВ. Морфология поверхности образцов контролировалась с помощью сканирующего электронного микроскопа Pioneer производства фирмы Raith при ускоряющем напряжении электронного пучка 10 кВ. СЭМизображения получали при использовании вертикального падении электронного пучка $\left(90^{\circ}\right)$ и при падении пучка под скользящим углом $\sim 7^{\circ}$ на поверхность образца.

Контроль толщины и фазового состава пленок методом спектральной эллипсометрии в наших экспериментах проводился на эллипсометре „Эллипс-1891“, изготовленном в Институте физики полупроводников им. А.В. Ржанова [11]. Эллипсометр создан на основе статической измерительной схемы, обеспечивающей высокую скорость измерений за счет отсутствия вращающихся элементов и модуляции сигнала. Время измерения на одной длине волны определяется только степенью инерционности электронно-усилительного тракта. Это позволяет достигать высокой точности измерений за счет накопления большого массива данных за небольшое время с последующим усреднением. В качестве источника света использовалась ксеноновая лампа мощностью $75 \mathrm{~B}$ с м монохроматором. Измерения проводились в спектральном диапазоне 250-1000 нм. Световое пятно имело форму эллипса $1 \times 3$ мм. В эксперименте были измерены спектры $\Psi(\lambda)$ и $\Delta(\lambda)$, из которых восстанавливались параметры исследуемых структур $\mathrm{SiO}_{2} / \mathrm{Si} / \mathrm{SiO}_{2} / \mathrm{Si}$. Оптические спектры отсеченного слоя $\mathrm{Si}$ моделировались как смесь аморфной $(a-\mathrm{Si})$ и кристаллической $(c-\mathrm{Si})$ фаз кремния с использованием модели эффективной среды. Процесс подгонки заключался в поиске толщины отсеченного слоя кремния и процентного соотношения 


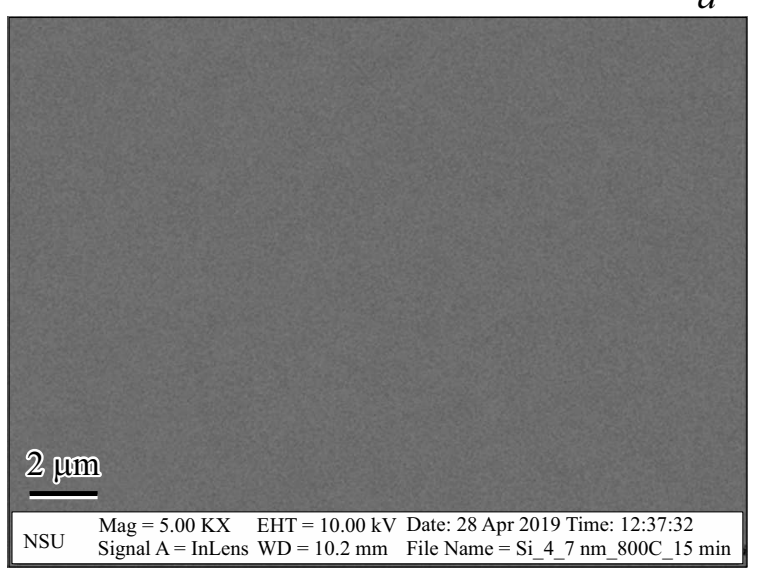

$c$

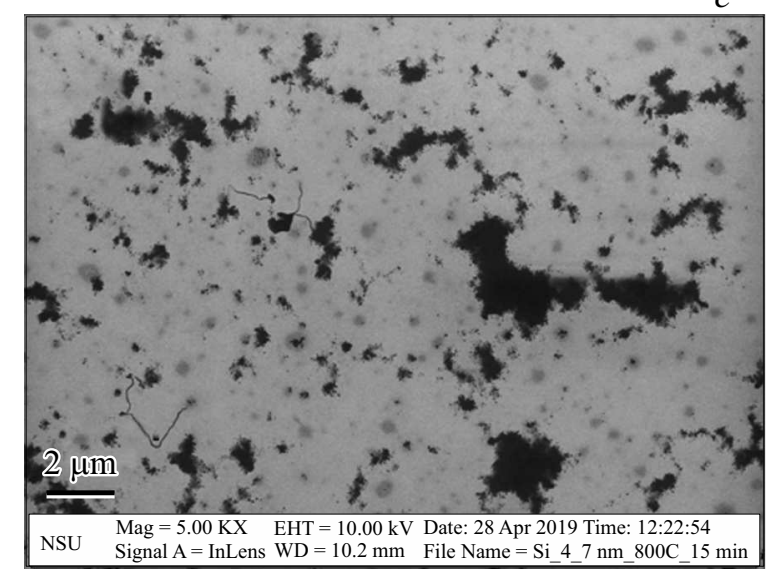

$b$

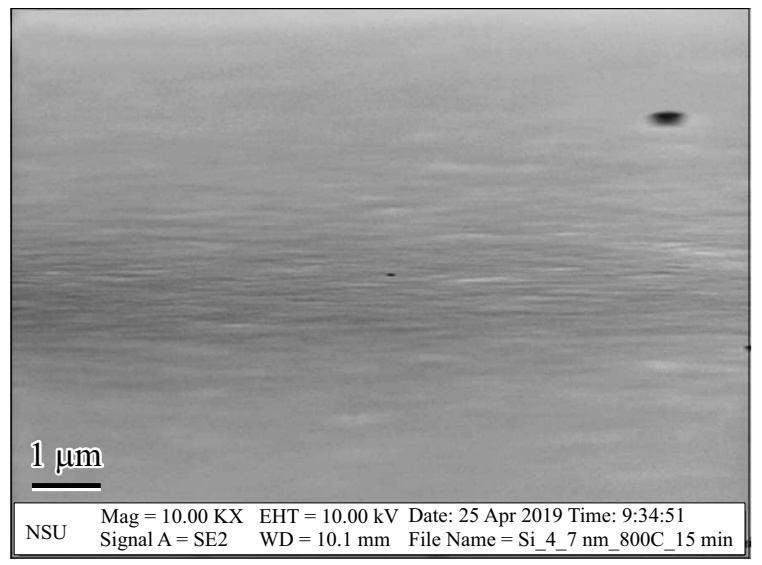

$d$

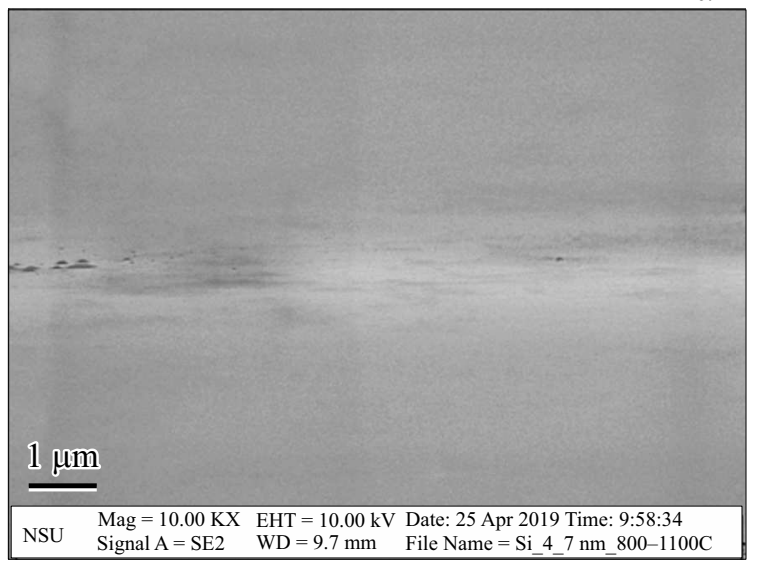

Рис. 1. СЭМ-изображения поверхности образца КНИ с исходной толщиной слоя кремния 4.7 нм после отжига при температурах $800(a, b)$ и $1100^{\circ} \mathrm{C}(c, d)$, под углом электронного пучка $90(a, c)$ и $7^{\circ}(b, d)$.

фаз $a$-Si и $c$-Si при условии максимального совпадения измеренного и модельного спектров. Точность определения составляла для толщины $\pm 0.1 \mathrm{Hм}$, для процентного содержания фаз $\pm 1 \%$.

\section{3. Результаты и обсуждение}

На рис. 1 представлены СЭМ-изображения поверхности образца КНИ с исходной толщиной слоя кремния 4.7 нм после отжига при температуре $800^{\circ} \mathrm{C}$, под углом электронного пучка $90^{\circ}$ (рис. $\left.1, a\right)$ и $7^{\circ}$ (рис. $1, b$ ). Из рисунка видно, что поверхность образца является ровной и не содержит микронеоднородностей и областей разрыва. Изображения поверхности этого же образца после отжига при температуре $1100^{\circ} \mathrm{C}$ приведены на рис. $1, c$ и $d$. Электронно-микроскопическое исследование показало, что увеличение температуры отжига привело к изменению морфологии поверхности. Пленка стала неоднородной, в ней появились разрывы (рис. 1,c). Эти же изменения видны и при скользящем угле падения электронов (рис. 1,d).
На рис. 2 показаны СЭМ-изображения поверхности образца КНИ с исходной толщиной слоя кремния $2.2 \mathrm{Hм}$ также после отжига при температурах 800 и $1100^{\circ} \mathrm{C}$ при нормальном и скользящем падениях электронного пучка. Из рис. 2, $a$ видно, что уже после отжига при температуре $800^{\circ} \mathrm{C}$ на поверхности пленки видны структурные неоднородности, которые могут быть связаны либо с разрывами в пленке, обусловленными ее термической нестабильностью, либо изменением ее стехиометрического состава. Увеличение температуры отжига до $1100^{\circ} \mathrm{C}$ приводит к тому, что разрывы становятся видны более отчетливо (рис. 2, $c$ и $d$ ). В пленке появились просветы между отдельными ее областями, которые стали электрически независимыми. При облучении электронным пучком это приводит к поляризации диэлектрика и, как следствие, к ухудшению контраста изображения (рис. 2, c) за счет возможной нестабильности пучка. При этом пленка все же не распалась на отдельные капли.

Кроме плавления, причиной появления разрывов в пленке могут быть деформации, обусловленные различием коэффициентов термического расширения пленок кремния и $\mathrm{SiO}_{2}$. Деформации, возникающие в тонкой пленке $\mathrm{Si}$, когда ее толщина существенно меньше тол- 
$a$
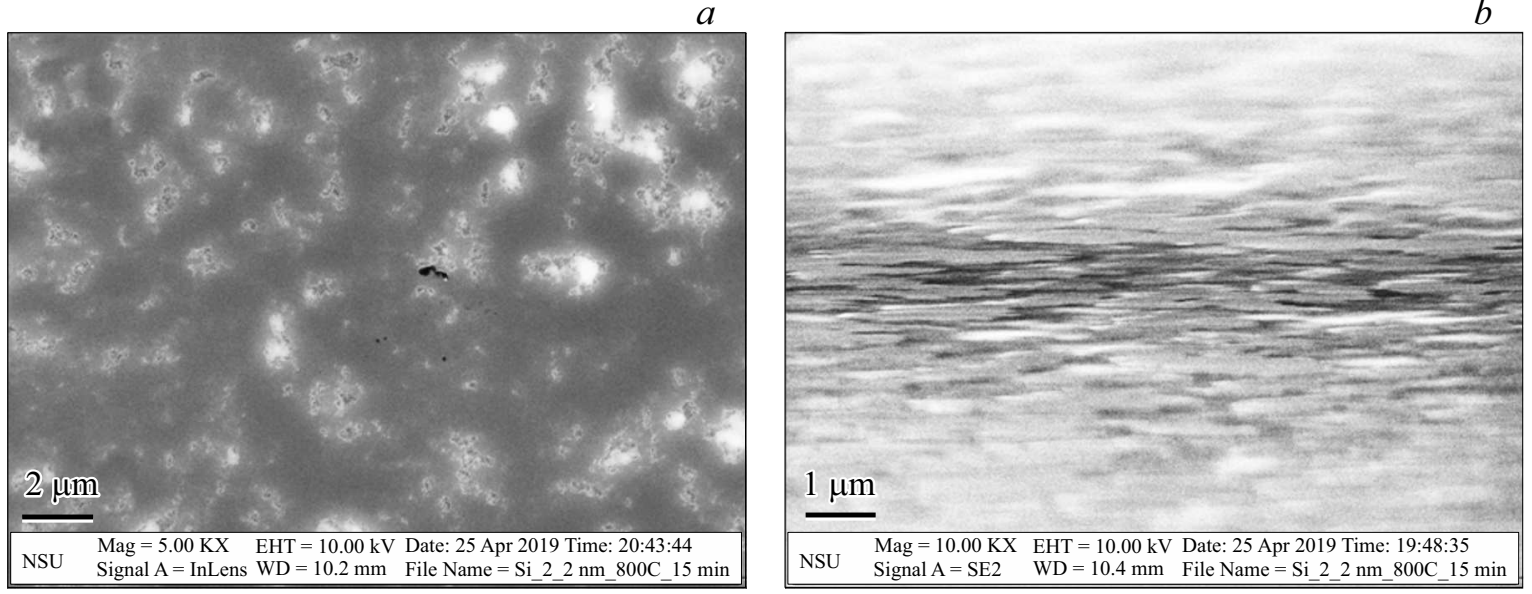

$c$
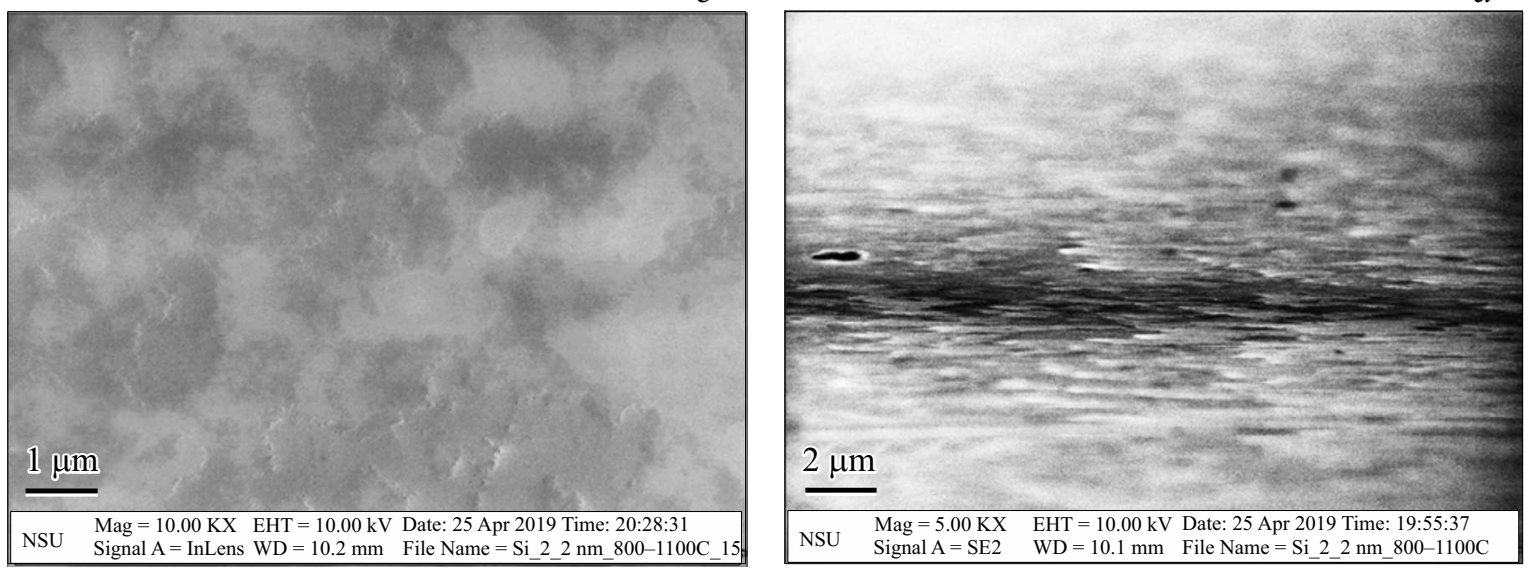

Рис. 2. СЭМ-изображения поверхности образца КНИ с исходной толщиной слоя кремния 2.2 нм после отжига при температурах $800(a, b)$ и $1100^{\circ} \mathrm{C}(c, d)$, под углом электронного пучка $90(a, c)$ и $7^{\circ}(b, d)$.

щины слоя $\mathrm{SiO}_{2}$, могут быть описаны выражением [12]:

$$
\varepsilon=\frac{\sigma}{E}(1-\mu)
$$

где $\varepsilon-$ деформация, $\sigma$ - напряжение, $E=163$ ГПа модуль Юнга $\mathrm{Si}, \mu=0.266$ - коэффициент Пуассона $\mathrm{Si}$. Напряжения, которые возникают в пленке из-за различия коэффициентов термического расширения со слоем $\mathrm{SiO}_{2}$, могут быть оценены как $\sigma=\left(\alpha_{\mathrm{Si}}-\alpha_{\mathrm{SiO}_{2}}\right) \Delta T E$, где $\alpha_{\mathrm{Si}}=2.33 \cdot 10^{-6} \mathrm{C}^{-1}-$ коэффициент термического расширения кремния, $\alpha_{\mathrm{SiO}_{2}}=5.5 \cdot 10^{-7} \mathrm{C}^{-1}-$ коэффициент термического расширения $\mathrm{SiO}_{2}$ [13]. После подстановки числовых значений в выражение (1) получим величину деформации для температуры отжига $1100^{\circ} \mathrm{C} \sim 2 \cdot 10^{-4}$. Полученная величина деформации недостаточна для того, чтобы привести к разрыву связей в кремнии.

С целью выяснения причины наблюдаемых структурных изменений в пленках КНИ были исследованы толщина пленки и ее стехиометрический состав в зависимости от температуры отжига методом спектральной эллипсометрии. На рис. 3 представлено изменение толщины пленки КНИ с исходным значением 4.7 нм с ро- стом температуры отжига. Из рисунка видно, что заметное уменьшение толщины пленки происходит начиная с температуры $900-1000^{\circ} \mathrm{C}$. Этот процесс может быть обусловлен окислением кремния за счет поступающего извне остаточного кислорода в атмосфере паров азота. Однако измерения показывают, что толщина верхнего слоя $\mathrm{SiO}_{2}$ остается практически неизменной и на протяжении всего эксперимента составляет 1.4-1.9 нм. Это указывает на то, что процесс окисления происходит со стороны захороненного слоя $\mathrm{SiO}_{2}$.

Наряду с уменьшением толщины слоя КНИ наблюдалось и изменение его фазового состава (рис. 4). Даже исходная пленка кремния толщиной 4.7 нм неоднородна по своему составу, и ее оптические характеристики соответствуют смеси фаз кристаллического (90\%) и аморфного (10\%) кремния. Начиная с температуры отжига $800^{\circ} \mathrm{C}$ доля аморфной фазы в пленке кремния начинает увеличиваться и после отжига при температуре $1100^{\circ} \mathrm{C}$ достигает $52 \%$.

Аналогичные зависимости толщины слоя кремния-наизоляторе и его стехиометрического состава от температуры последующего отжига были получены и для пленки с исходной толщиной 2.2 нм. Эти данные представлены 


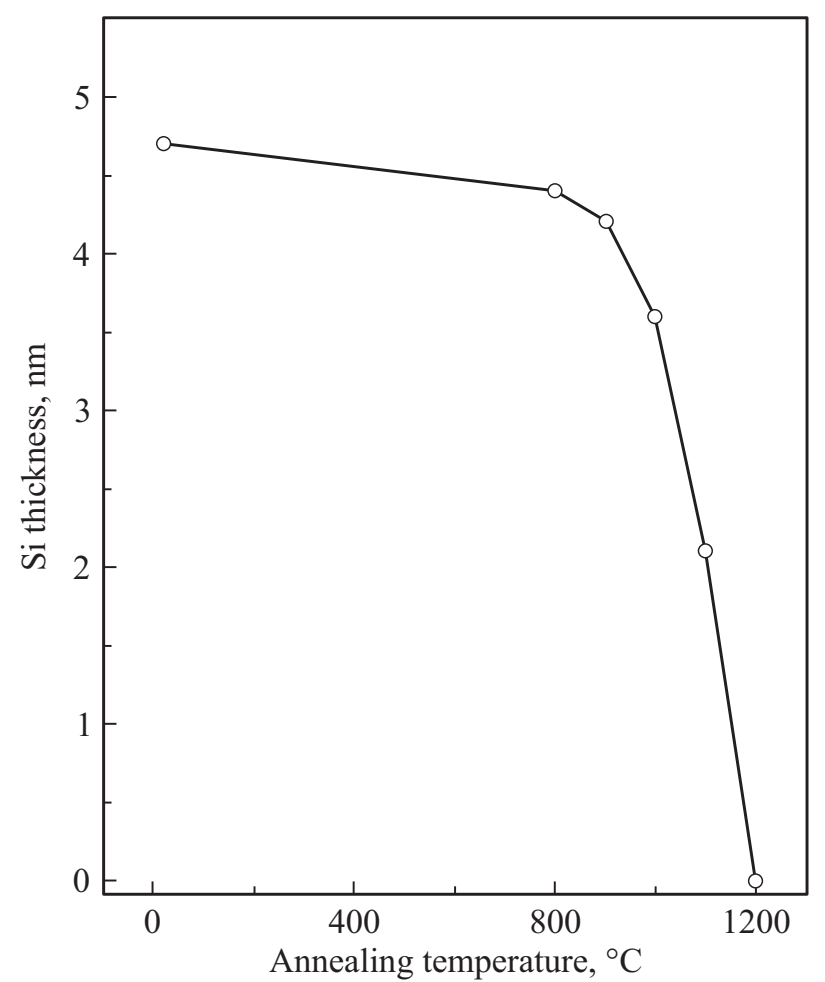

Рис. 3. Зависимость толщины пленки КНИ с исходным значением 4.7 нм от температуры отжига.

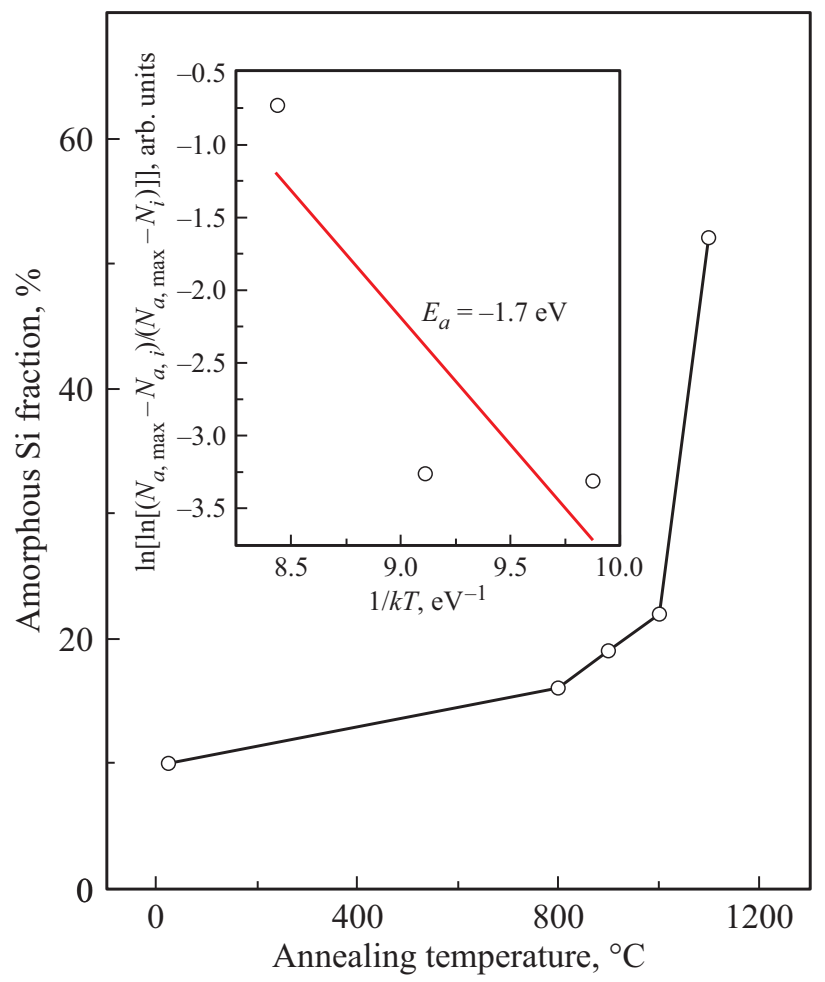

Рис. 4. Зависимость содержания аморфной фазы в пленке КНИ толщиной 4.7 нм от температуры отжига. На вставке показана зависимость Аррениуса. на рис. 5 и 6 соответственно. В этом случае уменьшение толщины пленки и рост аморфной фазы в ней также происходят начиная с температуры $800^{\circ} \mathrm{C}$, но эти изменения происходят быстрее, чем в пленках толщиной 4.7 нм. После отжига при температуре $1100^{\circ} \mathrm{C}$ доля аморфной фазы в пленке составляет $100 \%$, а толщина $-\sim 0.2$ нм.

При изохронном отжиге изменение доли аморфной фазы в пленках как функция температуры отжига, если не рассматривать обратный процесс восстановления кристаллической матрицы, можно описать уравнением реакции п-го порядка [14]:

$$
\frac{d N_{a}}{d t}=-K N_{a i}^{n}
$$

где $N$ - доля аморфной фазы в пленке, $K-$ скорость реакции аморфизации, $n-$ порядок реакции. Будем полагать, что постоянная скорости реакции $K$ не зависит от первоначального фазового состава пленки. Тогда она может быть описана формулой Аррениуса:

$$
K=K_{o} \exp \left(-\frac{E_{0}}{k T}\right),
$$

где $K_{o}-$ значение скорости реакции при $T \rightarrow \infty, E_{a}-$ энергия активации процесса. Граничные условия для нашего процесса можно записать в виде

$$
N_{a}(t ; T)=N_{a}(0 ; 0)+N_{c}(0 ; 0)-N_{c}(t ; T),
$$

где $N_{a}(t ; T)$ - доля кристаллической фазы в пленке после отжига при температуре $T$ в течение времени $t$; $N_{a}(0 ; 0)$ - доля аморфной фазы в исходной пленке; $N_{c}(0 ; 0)$ - доля кристаллической фазы в исходной пленке; $N_{c}(t ; T)$ - доля кристаллической фазы в пленке после отжига при температуре $T$ в течение времени $t$. Максимальное значение доли аморфной фазы в пленке равно:

$$
N_{a, \max }=N_{a}(0 ; 0)+N_{c}(0 ; 0) .
$$

Интегрирование уравнения (2) по времени $t$ для процесса первого порядка дает выражение

$$
\ln \left[\frac{N_{a, \max }-N_{a}(0)}{N_{a, \max }(T)-N_{a}(T)}\right]=K t .
$$

Для изохронного отжига, когда используется один и тот же образец, уравнение (6) может быть преобразовано в уравнение вида

$$
\ln \left[\frac{N_{a, \max }-N_{a, i-1}}{N_{a, \max }-N_{a, i}}\right]=K t .
$$

где $N_{a, i}$ - доля аморфной фазы после отжига при температуре $T_{i}$, а $N_{a, i-1}$ - доля аморфной фазы после предыдущего отжига. После подстановки выражения (7) в выражение (3) получим

$$
\ln \left[\frac{N_{a, \max }-N_{a, i-1}}{N_{a, \max }-N_{a, i}}\right]=K_{0} \exp \left(-\frac{E_{a}}{k T}\right) .
$$




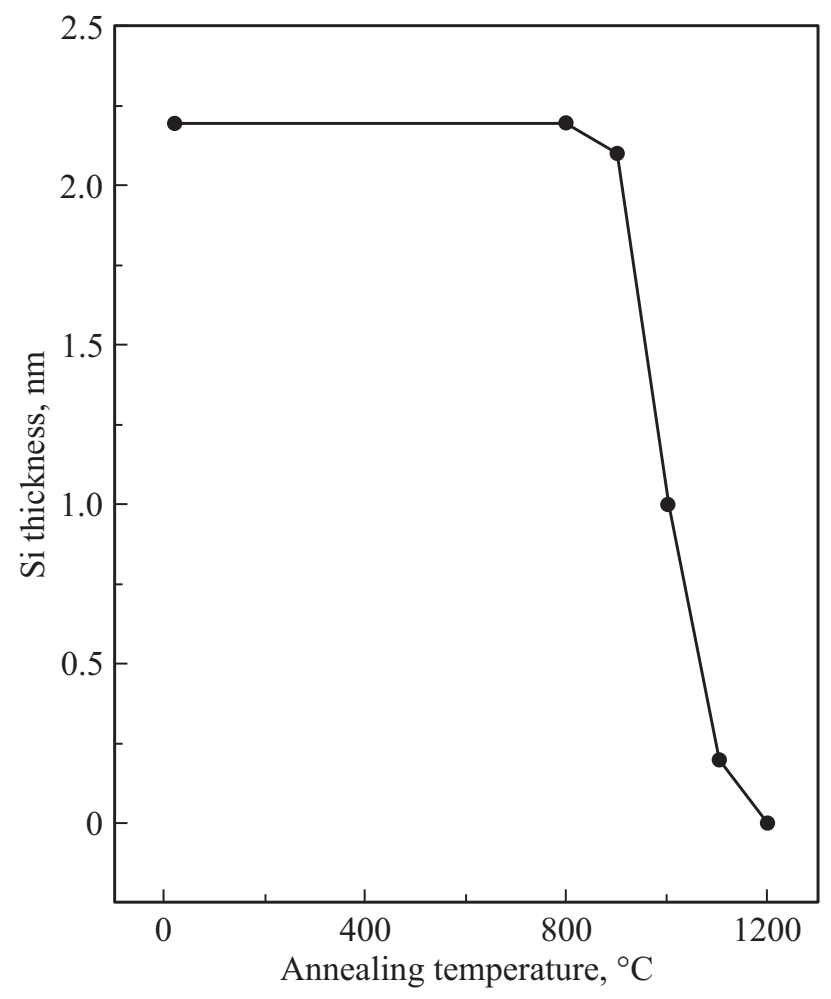

Рис. 5. Зависимость толщины пленки КНИ с исходным значением 2.2 нм от температуры отжига.

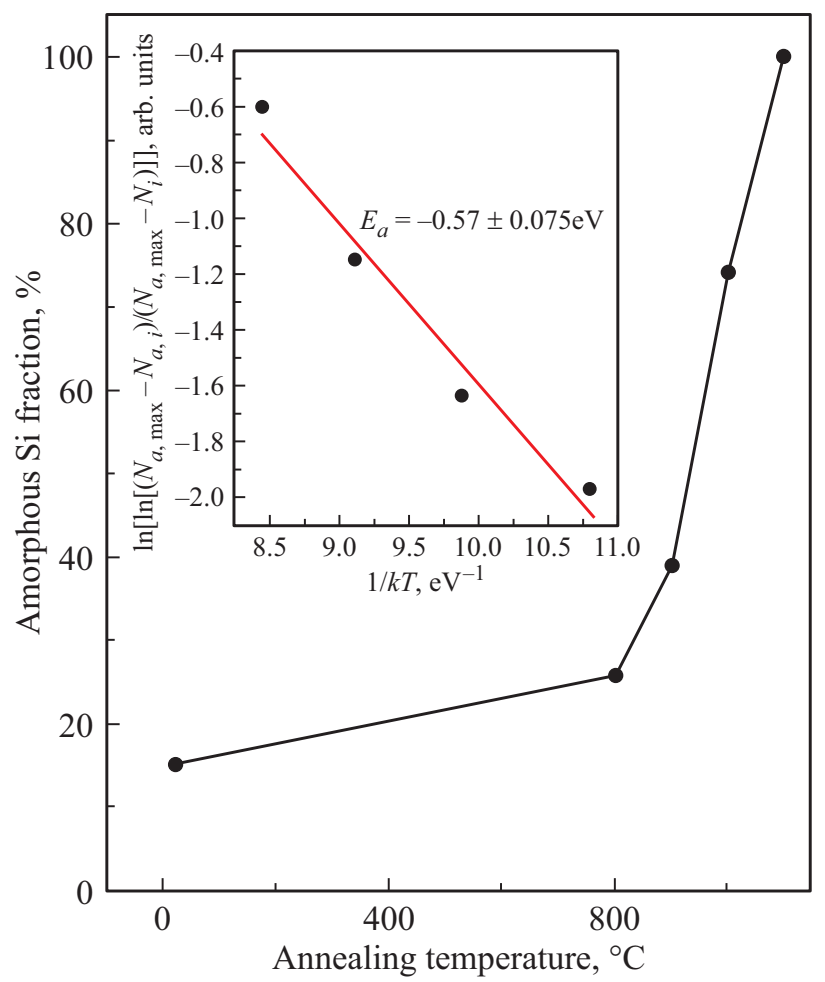

Рис. 6. Зависимость содержания аморфной фазы в пленке КНИ толщиной 2.2 нм от температуры отжига. На вставке показана зависимость Аррениуса.
Прологарифмировав выражение (8), получим зависимость вида

$$
\ln \left[\ln \left(\frac{N_{a, \max }-N_{a, i-1}}{N_{a, \max }-N_{a, i}}\right)\right]=\frac{K_{0}}{t}-\frac{E_{a}}{k T} .
$$

Построив зависимость $\ln \left[\ln \left(\frac{N_{a, \max }-N_{a, i-1}}{N_{a, \max }-N_{a, i}}\right)\right]$ от $1 / k T$, найдем значение энергии активации процесса аморфизации первого порядка. Для пленок кремния толщиной 4.7 и 2.2 нм эти зависимости представлены на вставках рис. 4 и 6 соответственно. Для пленок толщиной 4.7 нм энергия активации роста доли аморфной фазы составила $\sim 1.7$ эВ, а для пленок толщиной $2.2 \mathrm{Hм}-0.57$ эВ.

Наблюдаемые нами эффекты изменения толщины и стехиометрического состава пленок могут быть связаны с двумя основными процессами. Во-первых, с окислением пленок за счет взаимодействия с атомами остаточного кислорода в атмосфере $\mathrm{N}_{2}$, проникающими в пленку при отжиге. Однако результаты измерений показывают, что в процессе отжига толщина верхнего слоя $\mathrm{SiO}_{2}$ остается практически неизменной. Это означает, что термического окисления пленки со стороны поверхности не происходит. Действительно, процесс окисления в монокристаллическом кремнии происходит за счет взаимодействия диффундирующих извне атомов кислорода с присутствующими в нем равновесными при данной температуре вакансиями. В результате такого взаимодействия в решетку монокристаллического кремния генерируются межузельные атомы. В объемном монокристалле или в толстой пленке монокристаллического кремния эти межузельные атомы диффундируют вглубь и рекомбинируют с имеющимися там вакансиями кремния. В случае тонких пленок этот процесс ограничен объемом пленки и концентрацией имеющихся в нем свободных вакансий кремния. В пленке нанометровой толщины концентрация вакансий определяется не только температурой, но и концентрацией межузельных атомов кремния, диффузия которых в глубь пленки ограничена. Поэтому взаимодействие поступающего в пленку кислорода и атомов кремния затруднено. Это является причиной того, что пленки кремния толщиной $<10$ нм практически не окисляются [15]. Поэтому справедливо предположить, что окисление пленки происходит со стороны захороненного слоя $\mathrm{SiO}_{2}$ за счет диффузии атомов кислорода и взаимодействия их с ослабленными связями в переходном слое вблизи границы раздела $\mathrm{Si} / \mathrm{SiO}_{2}$. Кроме этого, атомы избыточного кислорода могут легко диффундировать сквозь пленку кремния в слой захороненного $\mathrm{SiO}_{2}$, в том числе и в форме несвязанной с решеткой молекулы $\mathrm{O}_{2}$ [16]. Коэффициент диффузии кислорода в кремнии при температуре $1100^{\circ} \mathrm{C}$ составляет $\sim 10^{-10} \mathrm{~cm}^{2} / \mathrm{c}$ [16]. За время отжига 15 мин это соответствует длине диффузии $\sim 3 \cdot 10^{-4} \mathrm{~cm}$, т.е. на 3 порядка величины больше толщины пленок, использованных нами в экспериментах.

Анализ активационных зависимостей (см. вставки к рис. 4 и 6) показывает, что они различны для пле- 
нок толщиной 4.7 и 2.2 нм. Энергия активации аморфизации пленок толщиной 4.7 нм составляет $\sim 1.7$ эВ (см. вставку к рис. 4). Энергия разрыва $\mathrm{Si}-\mathrm{Si}-$ связи в монокристаллическом кремнии составляет $\sim 1.8$ эВ [17]. В пленках нанометровой толщины средняя энергия Si-Siсвязи может быть меныше из-за уменьшения среднего значения координационного числа атомов. Уменьшение толщины пленки до 2.2 нм сопровождается уменьшением энергии активации образования аморфной фазы. Этот эффект также может быть связан с уменьшением средней энергии связи между атомами кремния из-за увеличивающегося вклада низкокоординированных атомов на поверхности. С другой стороны, уменьшение толщины пленок, связанное с их окислением, предполагает взаимодействие атомов кремния с атомами кислорода, диффундирующими из $\mathrm{SiO}_{2}$. Диффузия кислорода из слоя $\mathrm{SiO}_{2}$ к границе раздела $\mathrm{Si} / \mathrm{SiO}_{2}$ осуществляется в молекулярной форме $[18,19]$. В частности, было показано $[19,20]$, что для пленок кремния толщиной $>1.5$ нм кислород в атомарной форме находится лишь в непосредственной близости от границы раздела $\mathrm{Si} / \mathrm{SiO}_{2}$. Это означает, что для окисления кремния необходимы затраты энергии на диссоциацию молекулы $\mathrm{O}_{2}$, которая в оксиде кремния составляет $\sim 1.2$ эВ [17], и на преодоление энергетического барьера на взаимодействие с ослабленной Si-Si-связью, величина которого составляет $\sim 0.2-0.3$ эВ [21,22]. Суммарное значение этих энергий составляет $\sim 1.5$ эВ и близко к наблюдаемому экспериментально значению энергии активации на рис. 4. Генерация межузельных атомов в пленку $\mathrm{Si}$ при окислении также может приводить к росту доли аморфной фазы.

Возможной причиной уменьшения энергии активации образования аморфной фазы в пленках толщиной $2.2 \mathrm{Hм}$, по сравнению с пленками толщиной $4.7 \mathrm{HM}$, может быть их начальная структурная неоднородность (рис. 2). Поэтому процесс окисления в этих пленках может протекать как в плоскости границы раздела со слоем захороненного оксида кремния, так и в областях разрывов пленки. Механизм аморфизации таких пленок требует дальнейших исследований.

\section{4. Заключение}

Термическая стабильность и структурные изменения в пленках кремний-на-изоляторе толщиной 4.7 и $2.2 \mathrm{Hм}$ были исследованы после отжига при температурах $800-1200^{\circ}$ С. Исследования проводились методами сканирующей электронной микроскопии и спектральной эллипсометрии. Показано, что пленки остаются протяженными во всем изученном интервале температур отжига. С ростом температуры отжига наблюдается уменьшение толщины пленок и изменение их фазового состава. Обнаружено, что с увеличением температуры отжига доля кристаллической фазы в пленках уменьшается, а доля аморфной фазы растет. Энергия активации процесса аморфизации пленок различна для пленок 4.7 и 2.2 нм. Она составляет $\sim 1.7$ и 0.57 эВ соответственно. Полученные результаты обсуждаются с точки зрения диффузии атомов кислорода в пленку кремния и перестройки $\mathrm{Si}-\mathrm{Si}-$ связей.

\section{Финансирование работы}

Работа выполнена при поддержке Министерства образования и науки РФ (ГЗ 0242-2021-0003).

\section{Благодарности}

Авторы выражают благодарность А.А. Овчинникову за полезные обсуждения работы. Эксперименты проводились с использованием оборудования центра коллективного пользования ВТАН НГУ.

\section{Конфликт интересов}

Авторов заявляют об отсутствии конфликта интеpecoв.

\section{Список литературы}

[1] I.E. Tyschenko, V.P. Popov. In: Advances in Semiconductor Nanostructures: Growth, Characterization, Properties and Applications, ed. by A.V. Latyshev (Elsevier, 2016) p. 409.

[2] Y. Ono, M. Nagase, M. Tabe, Y. Takahashi. Jpn. J. Appl. Phys., 34, 1728 (1995) pt. 1.

[3] Y. Ishikawa, M. Kumezawa, R. Nuryadi, M. Tabe. Appl. Surf. Sci., 190, 11 (2002)

[4] Y. Ishikawa, Y. Imai, H. Ikeda, M. Tabe. Appl. Phys. Lett., 83, 3162 (2003).

[5] B. Legrand, V. Agache, T. Mélin, J.P. Nys, V. Senez, D. Stiévenard. J. Appl. Phys., 91, 106 (2002).

[6] R. Nuryadi, Y. Ishikawa, Y. Ono, M. Tabe. J. Vac. Sci. Technol. B, 20, 167 (2002).

[7] P. Pavlov. Z. Phys. Chem., 65, 1 (1908).

[8] F.A. Lindemann. Phys. Z., 11, 609 (1910).

[9] H. Reiss, I.B. Wilson. J. Colloid. Sci., 3, 551 (1948).

[10] F.G. Shi. J. Matter. Res., 9, 1307 (1994).

[11] С.В. Рыхлицкий, Е.В. Спесивцев, В.А. Швец, В.Ю. Прокопьев. Приборы и техника эксперимента, 2, 161 (2012).

[12] H.J. Oel, V.D. Frhchette. J. Amer. Ceram. Sci., 50, 542 (1967).

[13] K.E. Petersen. Proc. IEEE, 70, 420 (1982).

[14] H. Ryssel, I. Ruge. Ion implantation (Wiley, Chichester, 1986) p. 478

[15] В.А. Антонов, Е.В. Спесивцев, И.Е. Тысченко. ФТП, 45, 1121 (2011).

[16] U. Gösele, T.Y. Tan. Appl. Phys. A, 28, 79 (1982).

[17] B.E. Deal, A.S. Grove. J. Appl. Phys., 36, 3770 (1965).

[18] H.C. Lu, T. Gustafsson, E.P. Gusev, E. Garfunkel. Appl. Phys. Lett., 67, 1742 (1995).

[19] A.V. Fadeev, Yu.N. Devyatko. Techn. Phys., 64, 575 (2019).

[20] E.P. Gusev, H.C. Lu, T. Gustafsson, E. Garfunkel. Mater. Res. Soc. Symp. Proc., 318, 69 (1994).

[21] L. Tsetseris, S.T. Pantelides. Phys. Rev. Lett., 97, 116101 (2006).

[22] T. Akiyama, H. Kageshima. Surf. Sci., 576, L65 (2005).

Редактор Г.А. Оганесян 


\title{
Structural changes in nanometer-thick silicon-on-insulator films during high-temperature annealing
}

I.E. Tyschenko ${ }^{1}$, E.V. Spesivtsev ${ }^{1}$, A.A. Shklyaev ${ }^{1,2}$, V.P. Popov ${ }^{1}$

${ }^{1}$ Rzhanov Institute of Semiconductor Physics, 630090 Novosibirsk, Russia

${ }^{2}$ Novosibirsk State University, 630090 Novosibirsk, Russia

\begin{abstract}
The thermal stability of silicon-on-insulator films with a thickness of 4.7 and $2.2 \mathrm{~nm}$ was studied as a function of the annealing temperature in the range $T=800-1200^{\circ} \mathrm{C}$ by scanning electron microscopy and spectral ellipsometry. No melting features of the films were found. The films remained continuous over the annealing temperature range. A decrease in the thickness of the films and a change in their phase composition with an increase in temperature were found. According to spectral ellipsometry, as the annealing temperature increased, the content of the crystalline phase in the films decreases, and the content of the amorphous one increases. The activation energy of the film amorphization was estimated. The revealed properties are discussed in the frame of the oxygen atom diffusion in the silicon films and in the rearrangement of $\mathrm{Si}-\mathrm{Si}$ bonds.
\end{abstract}

